\title{
Experimental and Theoretical Energy Analysis of Two Types of Radiant Floor Heating Systems
}

\author{
Giulia Alessio ${ }^{1}$, Angelo Zarrella ${ }^{1}$, Pierfrancesco Brunello ${ }^{1}$, Fabrizio Pulga $^{2}$, Marco Della Bianca ${ }^{2}$, \\ Michele De Carli ${ }^{1}$ \\ ${ }^{1}$ Department of Industrial Engineering, University of Padua, 35131 Padova, Italy \\ ${ }^{2}$ Wavin Italia SpA, 45030 Santa Maria Maddalena (RO), Italy
}

\begin{abstract}
Field measurement and numerical simulations on a traditional radiant floor heating system and a radiant floor system with a reduced thickness of the screed are presented, with the aim of comparing their performance. The environmental measurements were used to validate a numerical model which takes into account the dynamic behaviour of building structures as well as the transient operation of heat-carrier fluid in the embedded pipes. Simulations under the same boundary conditions were then performed and no significant difference was found in the energy performance of the two floor systems. From the analysis of the temperature inside the rooms, a negligible difference was found between air and operative temperature for both the radiant systems.
\end{abstract}

\section{Introduction}

Radiant systems are being used for heating and cooling purposes for a long time (Shoemaker, 1954; Olesen, 1997) and standardized methods are today available for the sizing (ISO 11855), but there are questions which are still open and under discussion. In particular, in new and retrofitted buildings, where the envelope presents high levels of insulation, it is argued if it is better to have low or high inertia radiant systems for controlling the indoor operative temperature and avoid overheating, especially in mid seasons when outdoor temperature is mild and solar radiation is high.

Besides traditional floor systems and dry floor systems, a new type of floor system recently started to spread in the market. It is a wet floor system with a reduced thickness of the screed, which is useful in situations where there are problems of height (e.g. retrofit of existing buildings) and which has a faster thermal response if compared to a traditional floor system. Despite being part of a wellknown technology, designers and practitioners frequently ask if these newly-developed systems perform better than the traditional ones and if energy saving can be achieved when they are used in intermittent operation.

To investigate the energy performance of this new type of radiant floor, measurements are needed, along with dynamic simulations properly taking into account the dynamic behaviour of building structures as well as the transient operation of water in the embedded pipes. Dealing with field measurements involving systems like heating/cooling plants coupled with buildings is generally a complex matter and most of the times the mere energy measurements cannot lead to immediate conclusions on the energy performance of the analysed systems. In particular, when two systems are under comparison, it is very difficult to perform measurements in exactly the same conditions, because different orientations of the buildings, different internal loads when the buildings are inhabited, different weather conditions and different boundary temperature are elements which cannot usually be all avoided. Simulations are therefore needed to compare the systems under the same boundary conditions and data from measurements are very useful to tune the models.

In the present work the floor radiant systems of two flats in a new building not yet inhabited were considered for the analyses. Continuous temperature monitoring was planned with continuous and intermittent operation of the heating systems and the measurements were used to check the air and surface temperature trends resulting from multi-room simulations with the numerical model DIGITHON (De Carli et al., 2012). Dynamic simulations of the two systems were then performed under the same boundary conditions. Both continuous and intermittent operation were considered. Two possibilities were taken into account for the temperature difference from the generation side, which could be limited to $5 \mathrm{~K}$ or unlimited. The resulting energy need, operative and air temperatures and floor surface temperature were compared.

\section{Method}

\section{Case study and measurement set-up}

Two flats with a floor area of about $110 \mathrm{~m}^{2}$ were considered as case study. They are located on the ground floor of a new building in Padova (North-East of Italy). The orientation is North-West for Flat 1, South-West for Flat 2, and the internal distribution is the same.

Figure 1 shows the two rooms of each flat that were considered in the analysis. These two rooms have the same orientation and are not contiguous to the garages. Room 1 (floor area of about $10.6 \mathrm{~m}^{2}$ ) presents wooden floor, while Room 2 (floor area of about $6.0 \mathrm{~m}^{2}$ ) is a bathroom with ceramic tiles.

The external walls are made of wood-fiber cement formwork blocks. The U-values of the building structures are listed in Table 1. 


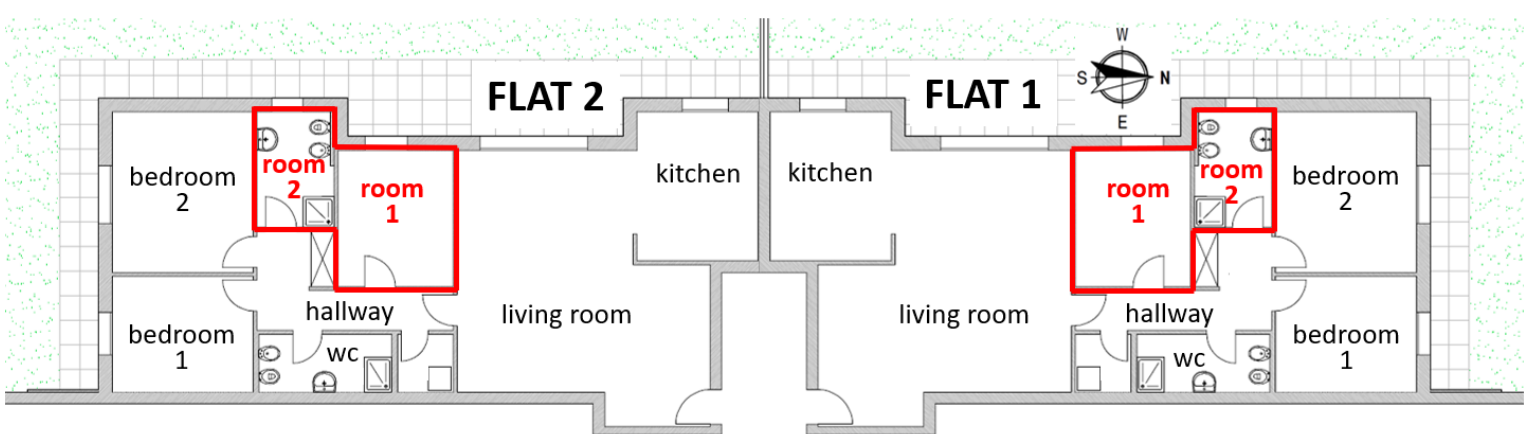

Figure 1: The flats and the rooms considered for measurements and simulations.

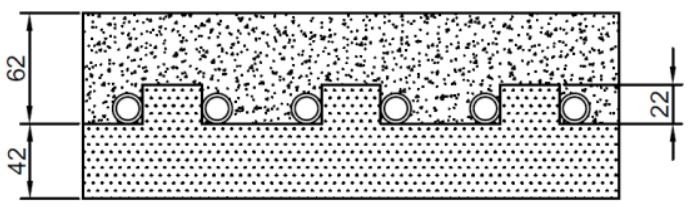

SYSTEM 1

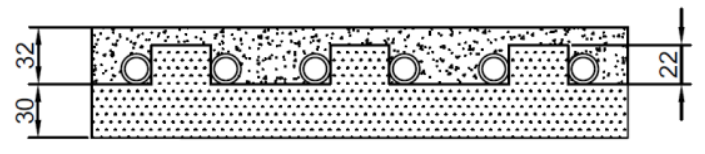

SYSTEM 2

Figure 2: The radiant systems in Flat 1 (left) and Flat 2 (right).

Table 1: Thermal transmittances of the building.

\begin{tabular}{|c|c|}
\hline Building structure & U-value $\left[\mathrm{W} \mathrm{m}^{-2} \mathrm{~K}^{-1}\right]$ \\
\hline External walls & 0.24 \\
\hline Internal walls & 1.84 \\
\hline Floor (Flat 1) & 0.29 \\
\hline Floor (Flat 2) & 0.32 \\
\hline Ceiling & 0.31 \\
\hline Windows & 0.71 \\
\hline
\end{tabular}

The floor radiant system in Flat 1 (System 1) is a traditional system, with cement and sand screed, while the radiant system in Flat 2 (System 2) presents a reduced thickness of the screed, which is a self-leveling one, and with a higher thermal conductivity compared to the traditional system. The two systems are represented in Figure 2. The thickness of the screed above the clew is $40 \mathrm{~mm}$ in System 1 and only $10 \mathrm{~mm}$ in System 2. Another difference is about the clew of the insulation panels, which is solid in System 1 and empty in System 2, allowing a uniform thickness of the screed. The properties of the screed and of the insulation panels are reported in Table 2 and Table 3.

Table 2: Properties of the screed.

\begin{tabular}{|c|c|c|}
\hline & Flat 1 & Flat 2 \\
\hline Thermal conductivity & $1.31 \mathrm{~W} \mathrm{~m}^{-1} \mathrm{~K}^{-1}$ & $1.87 \mathrm{~W} \mathrm{~m}^{-1} \mathrm{~K}^{-1}$ \\
\hline Thermal capacity & $1.00 \mathrm{~kJ} \mathrm{~kg}^{-1} \mathrm{~K}^{-1}$ & $1.00 \mathrm{~kJ} \mathrm{~kg}^{-1} \mathrm{~K}^{-1}$ \\
\hline Density & $1600 \mathrm{~kg} \mathrm{~m}^{-3}$ & $2000 \mathrm{~kg} \mathrm{~m}^{-3}$ \\
\hline
\end{tabular}

Table 3: Properties of the insulation.

\begin{tabular}{|c|c|c|}
\hline & Flat 1 & Flat 2 \\
\hline Thermal conductivity & $0.031 \mathrm{~W} \mathrm{~m}^{-1} \mathrm{~K}^{-1}$ & $0.023 \mathrm{~W} \mathrm{~m}^{-1} \mathrm{~K}^{-1}$ \\
\hline Thermal capacity & $1.45 \mathrm{~kJ} \mathrm{~kg}^{-1} \mathrm{~K}^{-1}$ & $1.40 \mathrm{~kJ} \mathrm{~kg}^{-1} \mathrm{~K}^{-1}$ \\
\hline Density & $25 \mathrm{~kg} \mathrm{~m}^{-3}$ & $35 \mathrm{~kg} \mathrm{~m}^{-3}$ \\
\hline
\end{tabular}

The same type of pipe is used in the two flats. It is a PERT pipe with an internal diameter of $13 \mathrm{~mm}$. Also the pipe spacing is the same in the two flats: $15 \mathrm{~cm}$ in Room 1 and $5 \mathrm{~cm}$ in Room 2.

The radiant loops of the two heated rooms were controlled by the same thermostat (on-off control with a band of $\pm 0.1^{\circ} \mathrm{C}$ ), placed in Room 1 , while the other rooms of the flat were unheated. The measuring points of Flat 2 can be seen in Figure 3; for Flat 1 the set-up was the same.

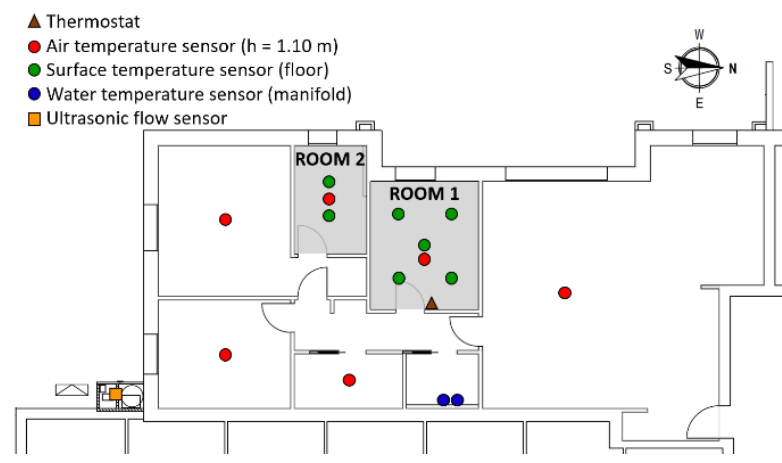

Figure 3: Position of the sensors in Flat 2.

The temperatures inside the flats and the external air temperature were monitored with NTC thermistors. Also the air temperature in the rooms above the heated ones was measured, with an accuracy of $\pm 0.35 \mathrm{~K}$. The supply and return fluid temperature were measured on the manifold by means of NTC thermistors, while an ultrasonic flow sensor placed on the air-to-water heat pump was used to measure the fluid flow rate, recording the maximum, minimum and mean value which occurred in an hourly based interval. The acquisition system recorded all the data with a time step of 5 minutes.

\section{Simulation model}

In order to reproduce the dynamic behaviour of the radiant systems of the two analysed flats, the numerical model DIGITHON was used (De Carli et al., 2012). This model performs the detailed simulation of the dynamic behaviour of water-based surface heating and cooling systems.

To solve the dynamic heat transfer problem in DIGITHON, the response factor technique is used (Stephenson and Mitalas, 1967; Kusuda, 1969). In the present work the heat transfer response factors were calculated by using the commercial software HEAT2 (Blomberg, 1999), which is based on the Finite Difference 
Method (FDM). Three simulations must be performed to describe the heat conduction in a building structure with embedded pipes. In each simulation a triangular impulse of temperature is given on the inner surface, on the outer surface and on the internal surface of the pipes, thus the resulting heat flows on the three surfaces are recorded. After normalization, for a generic trend of temperature on the inner surface of the building structure, on the outer surface of the building structure and on the internal surface of the pipe, the response factor can be used, by superposing of effects, to calculate the specific heat fluxes on the three considered surfaces. More details about this method, included an example showing its accuracy, can be found in De Carli and Tonon (2011).

In the model DIGITHON, each surface of the simulated rooms is divided into elements named tiles (Figure 4) and an overall heat balance is carried out for each element, considering the following thermal nodes:

- the air of the room, considered as a single uniform volume;

- the surface (inner and outer sides) of each tile of the walls, the floor and the ceiling;

- the water inside each pipe segment;

- the surfaces of each pipe segment.
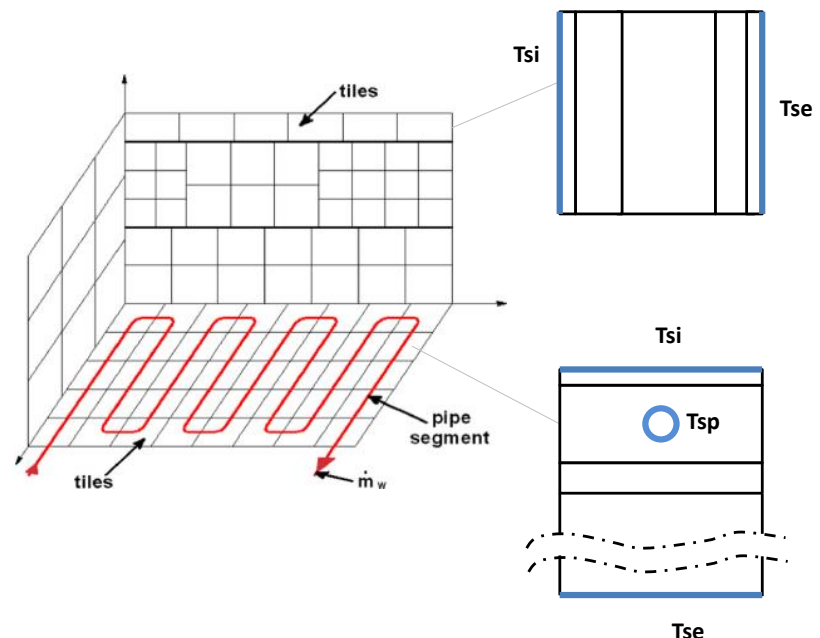

Figure 4: Example of discretization of a room equipped with a radiant floor system (De Carli et al., 2012) with the relevant surfaces where the heat balance is solved for structures with or without embedded pipes.

The convective heat flux for the $\mathrm{j}$-th general surface element $q_{c, j}$ is expressed as:

$$
q_{c, j}=h_{c, j} S_{j}\left(T_{s, j}-T_{f, j}\right)
$$

where $T_{s, j}$ is the surface temperature of the element and $T_{f, j}$ is the air temperature of the room (for the inner surface elements), the air temperature of the adjacent room (in case of internal walls) or the sol-air temperature (in case of outdoor surface). In rooms with conventional dimensions (less than $3 \mathrm{~m}$ high) the air temperature can be assumed to be uniform both in heating (Berglund and Gagge, 1985) and in cooling conditions (Külpmann, 1993) for radiant systems as well as in a wide range of situations that have been confirmed by other studies (Fischer and Pedersen, 1997). As regards convective heat transfer coefficients $h_{c, j}$, the most reliable analyses are those based on measurements in real size test rooms (De Carli and Tomasi, 2009). As shown in De Carli et al. (2012), constant values can be considered for the convective heat transfer coefficients and this was assumed in the calculations.

Assuming near-black surfaces and small temperature differences, the radiative heat exchange between the $\mathrm{j}$-th and the k-th surface can be expressed as:

$$
q_{r, j-k}=F_{j-k} h_{r} S_{j}\left(T_{s, j}-T_{s, k}\right)
$$

Thanks to the fine surface discretisation, the view factors $F_{j-k}$ are calculated in a detailed way in the model.

Shortwave radiation entering from glazing elements has to be summed on the right side of Equation (2), as well as the internal radiant gains. As shown in detail in De Carli and Tonon (2011), there is no difference in the overall heat balance when considering solar radiation distributed in detail or uniformly distributed; hence in the present model solar radiation is considered as uniformly diffused.

For the room air thermal node, the following equation can be written:

$$
\begin{aligned}
& \sum_{j}\left[h_{c, j} S_{j}\left(T_{s, j}-T_{a}\right)\right]+q_{\text {int }, c}= \\
& \frac{M_{a} c_{v}\left(T_{a}-\left(T_{a}\right)_{-\Delta \tau}\right)}{\Delta \tau}+\sum_{b} m_{b} c_{p} T_{b}
\end{aligned}
$$

where air flow rates enter in the room at a given temperature (the external temperature for infiltration or a known inlet temperature for mechanical ventilation) and leave at room temperature.

Considering the water inside each pipe segment, the temperature difference between two adjacent building elements is very small thanks to the discretisation, thus a linear trend of the temperature can be assumed. The equation can be written as follows:

$$
\begin{gathered}
{\left[h_{c, w} S_{p}\left(T_{s, p}-T_{w}\right)\right]=} \\
\frac{M_{w} c_{w}\left(T_{w}-\left(T_{w}\right)_{-\Delta \tau}\right)}{\Delta \tau}+m_{w} c_{w}\left(T_{w, o}-T_{w, i}\right)
\end{gathered}
$$

where $T_{w, i}$ and $T_{w, o}$ are respectively the inlet and outlet temperatures in the pipe element.

A suitable discretisation of the time domain is assumed: in the present study the interval $\Delta \tau$ is equal to 10 minutes. All the equations are linear, therefore the model can be expressed as linear system of equations which provides as results the inner side temperature and the heat flow of each surface element, the air temperature and the return water temperature of the radiant system. More details on the numerical model DIGITHON can be found in De Carli et al. (2012).

\section{Weather data}

As it has been already seen, the outdoor air temperature was measured at the building site, while for the solar radiation the data provided by the regional environmental protection agency ARPAV (ARPAV, 2018) were used. The solar radiation value taken by ARPAV is on the horizontal surface, while for the simulations the direct normal solar radiation and the diffuse solar radiation on 
the normal plane were needed as input. For this purpose TRNSYS was used, by means of the Type16, which takes the total horizontal solar radiation and computes the diffuse fraction using an algorithm that estimates cloudiness based on dry bulb and dew point temperature (Klein et al., 2011).

\section{Field measurements and model validation}

Two periods of 6 days each were considered for comparison between measurements and simulations (Table 4). A constant supply fluid temperature was set on the heat pump of each flat; during continuous operation the thermostat placed in Room 1 was set to $21^{\circ} \mathrm{C}$, while during intermittent operation it was scheduled as outlined in Table 5.

Table 4: Periods of field measurements.

\begin{tabular}{|c|c|c|}
\hline Period & $\begin{array}{c}\text { Operation } \\
\text { modality }\end{array}$ & $\begin{array}{c}\text { Supply water } \\
\text { temperature }\end{array}$ \\
\hline $8^{\text {th }}-14^{\text {th }}$ March 2018 & intermittent & $30^{\circ} \mathrm{C}$ \\
\hline $16^{\text {th }}-22^{\text {nd }}$ March 2018 & continuous & $40^{\circ} \mathrm{C}$ \\
\hline
\end{tabular}

Table 5: Schedule for the thermostat set-point during intermittent operation.

\begin{tabular}{|c|c|}
\hline Time & Air temperature set-point (Room 1) \\
\hline $6 \mathrm{am}-9 \mathrm{am}$ & $2{ }^{\circ} \mathrm{C}$ \\
\hline $9 \mathrm{am}-4 \mathrm{pm}$ & $15^{\circ} \mathrm{C}$ \\
\hline $4 \mathrm{pm}-10 \mathrm{pm}$ & $21^{\circ} \mathrm{C}$ \\
\hline $10 \mathrm{pm}-6 \mathrm{am}$ & $18^{\circ} \mathrm{C}$ \\
\hline
\end{tabular}

From the analysis of the thermostat state, recorded with a time step of 5 minutes, almost the same number of hours of operation of the circulation pump was found for the two radiant systems in the period from $8^{\text {th }}$ March to $13^{\text {rd }}$ March (98 hours in Flat 1 and 93 hours in Flat 2). In the period of continuous operation, the difference was higher (110 hours in Flat 1 and 95 hours in Flat 2). The radiant system of Flat 2 worked for a lower time than the system in Flat 1 not only because of the lower inertia and of the higher useful heat flux when the water temperature is the same, but also because of the better orientation (South-West instead of North-West for Flat 1) which ensured a higher temperature in the unheated rooms adjacent to Room 1 and Room 2. Because of the small on-off band of the thermostat $\left( \pm 0.1^{\circ} \mathrm{C}\right)$, on-off operations were very frequent: rarely the systems were switched on for more than one consecutive hour and most of the time they were on for less than half an hour, with many periods on for only 10-15 minutes.

The mean value of the air temperature measured from the sensor placed in the centre of each room and from the sensor of the thermostat (only in Room 1) are shown in Table 6. During the period of continuous operation, with the thermostat constantly set to $21^{\circ} \mathrm{C}$, the mean value of the air temperature measured in the centre of the Room 1 was equal to $20.7^{\circ} \mathrm{C}$ in Flat 1 and $20.9^{\circ} \mathrm{C}$ in Flat 2, with a standard deviation of $0.1^{\circ} \mathrm{C}$ in both the cases. The mean value recorded by the thermostat sensor, placed near the door, were the same than in the centre of the room, but higher fluctuations were found for the thermostat in Flat 1, as it can be seen in Figure 5. The thermostat of Flat 1 was probably affected by higher air movements due to infiltration from the unheated hallway than the thermostat of Flat 2. During the period of intermittent operation, a difference of about $0.5^{\circ} \mathrm{C}$ was found between the centre of the room and the thermostat position (at the same height).

In Table 6 also the mean value of the surface temperature measured from the sensors placed on the floor of each room are shown. In the week of continuous operation the surface temperature of the thin-screed radiant floor system (Flat 2) was $0.6^{\circ} \mathrm{C}$ higher than surface temperature of the traditional system (Flat 1), with both the coverings. The floor surface temperature in Flat 2 presented a higher number of oscillations (i.e. a higher number of on-off cycles) than in Flat 1. In the rooms with parquet covering (Room 1) the oscillation amplitude was lower than in the rooms with ceramic tiles (Room 2).

A multi-room model was built to compare the performance of the two radiant systems and data from measurements were used to tune the model. The air

Table 6: Comparison between measurements and simulations: mean value of the air temperature and of the surface temperature of the floor.

\begin{tabular}{|c|c|c|c|c|c|c|}
\hline \multirow{2}{*}{ Flat } & \multirow{2}{*}{$\begin{array}{l}\text { Operation } \\
\text { modality }\end{array}$} & \multirow{2}{*}{$\begin{array}{l}\text { measurements/ } \\
\text { simulation }\end{array}$} & \multicolumn{2}{|c|}{$\mathrm{T}_{\text {air }}\left[{ }^{\circ} \mathrm{C}\right]$} & \multicolumn{2}{|c|}{$\mathrm{T}_{\mathrm{S}}\left[{ }^{\circ} \mathrm{C}\right]$} \\
\hline & & & Room 1 & Room 2 & Room 1 & Room 2 \\
\hline \multirow{3}{*}{1} & \multirow{3}{*}{ continuous } & measurements & $20.7 * 20.7 * *$ & 21.2 & 24.6 & 28.1 \\
\hline & & ST & 21.0 & 23.8 & 23.6 & 28.8 \\
\hline & & SO & 21.3 & 24.3 & 23.9 & 29.7 \\
\hline \multirow{3}{*}{2} & \multirow{3}{*}{ continuous } & measurements & $20.9 * 20.9 * *$ & 24.2 & 25.2 & 28.7 \\
\hline & & ST & 21.0 & 25.0 & 23.8 & 30.5 \\
\hline & & $\mathrm{SO}$ & 21.1 & 25.2 & 23.9 & 30.9 \\
\hline \multirow{3}{*}{1} & \multirow{3}{*}{ intermittent } & measurements & $17.1 * 16.7^{* *}$ & 17.0 & 19.7 & 22.1 \\
\hline & & ST & 17.8 & 19.3 & 19.6 & 23.0 \\
\hline & & SO & 17.8 & 19.3 & 19.5 & 23.0 \\
\hline \multirow{3}{*}{2} & \multirow{3}{*}{ intermittent } & measurements & $17.6 * 17.0 * *$ & 18.2 & 19.9 & 22.2 \\
\hline & & ST & 18.0 & 20.2 & 19.7 & 23.6 \\
\hline & & SO & 18.2 & 20.4 & 19.9 & 24.0 \\
\hline
\end{tabular}


temperature recorded from the sensors in the rooms adjacent to the heated ones were used as boundary conditions in the simulations of the two heated rooms. Also the supply fluid temperature and the mass flow rate were taken from field measurements. For the supply fluid temperature measured on the manifolds were lower than the temperature set on the heat pump: $28^{\circ} \mathrm{C}$ in the period of intermittent operation and $35^{\circ} \mathrm{C}$ in the period of continuous operation. The mass flow rate was taken from the uninterrupted period of operation between $15^{\text {th }}$ and 16 ${ }^{\text {th }}$ March: $507 \mathrm{~L} / \mathrm{h}$ for Flat 1 and $523 \mathrm{~L} / \mathrm{h}$ for Flat 2 . A constant value of $10^{\circ} \mathrm{C}$ was used for the ground temperature and an air change of $0.15 \mathrm{~h}^{-1}$ was set. Internal gains were not considered, since the flat were empty during measurements.

Two kinds of simulations were performed for each period and each system: in one simulation a thermostat was set using the same schedules of the measurements and the radiant system turned on/off according to the air temperature reached in the room (simulation ST), in the other simulation the state of the radiant system was defined as input and the air temperature was not controlled (simulation $S O$ ). The calculation time step was set to 10 minutes.

The mean value of the air temperature and of the surface temperature of the floor resulting from the simulations are shown in Table 6 , along with the mean temperatures from field measurements. In general, a good compliance between simulated and measured air temperature was found in Room 1, with a root-mean-square error in the range $0.2-0.7^{\circ} \mathrm{C}$ during continuous operation, $1.1-1.3^{\circ} \mathrm{C}$ and $0.6-0.8^{\circ} \mathrm{C}$ during intermittent operation considering the sensor in the centre of the room and the thermostat sensor respectively. The root-mean-square error between simulated and measured mean surface temperature is in the range $0.9-1.4^{\circ} \mathrm{C}$ for Room 1 during continuous operation and $0.6-0.8^{\circ} \mathrm{C}$ during intermittent operation.

A graphical comparison of the measured and simulated temperatures is shown in Figure 5, where the results for simulations SO of Room 1 are plotted.

The results of the simulations can be considered good, since:

- some input data were assumed (ground temperature, infiltration rate);

- the beam and diffuse part of the solar radiation (which was not measured in-situ) were calculated using an algorithm which estimates cloudiness;

- the material properties of the building structures were partly assumed;

- a constant supply water temperature was used, without considering the effects of the heat pump operation on the water temperature;

- a constant water flow-rate was used, since from the field measurements only the mean hourly value was known and only for the period of continuous operation;

- the water flow-rate was considered to be equally distributed in the two rooms of each flat, since there was no possibility to measure it in the two loops.
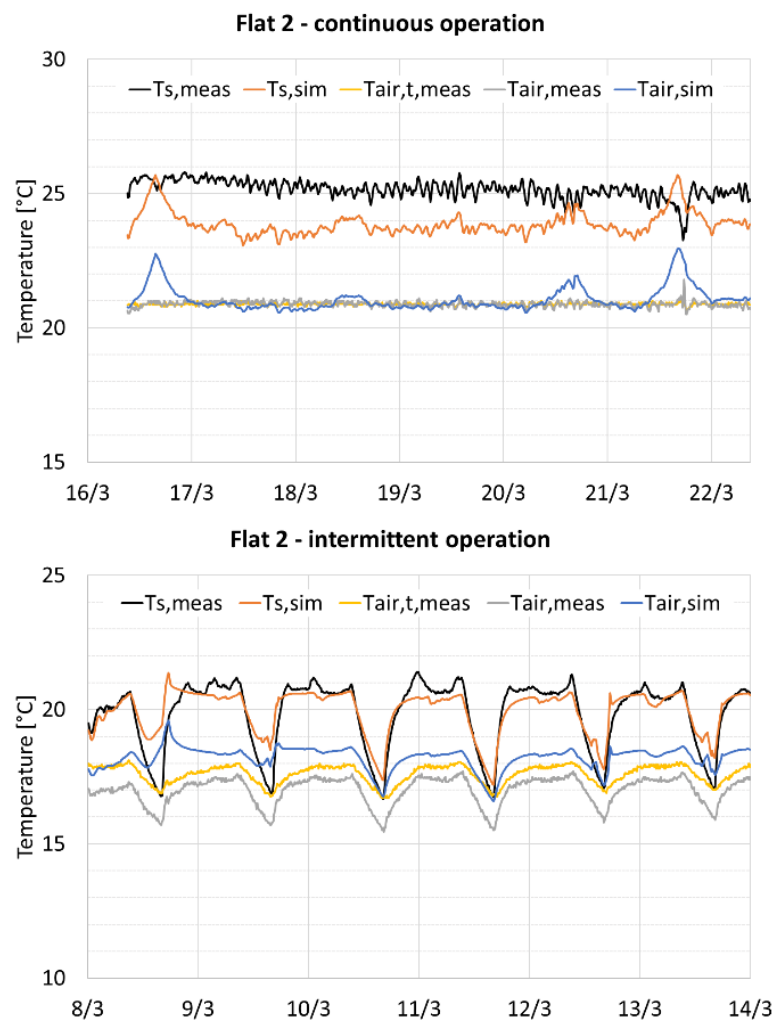

Figure 5: Comparison between measurements and simulations SO for Room 1: surface temperature of the floor and air temperature (thermostat sensor and sensor in the centre of the room) 


\section{Comparison of the two radiant systems}

The models of the two rooms were then used to compare the performance of the two different kinds of radiant floor heating systems under the same boundary conditions.

The simulations were performed using the weather data of Padova provided by ARPAV for the heating season 2017-2018. Two months were chosen for the simulations:

- December 2017, which is the month with the lowest mean air temperature;

- March 2018, which is a mid-season month with high global solar radiation.

The air temperature trend of the selected months is shown in Figure 6.

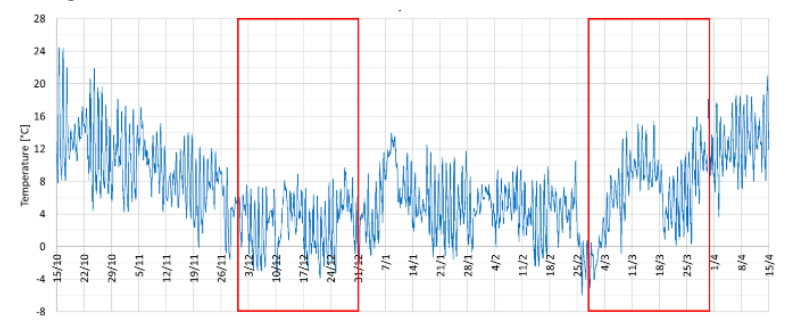

Figure 6: External air temperature and months chosen for the simulations.

The traditional radiant floor system (System 1) and the thin-screed radiant floor system (System 2) were simulated in continuous and intermittent operation considering the geometrical model of Flat 1 . The settings for the simulation are summarized in the following points:

- air temperature set-point: during continuous operation $20^{\circ} \mathrm{C}$ in Room 1 and $24^{\circ} \mathrm{C}$ in Room 2, during intermittent operation according to Table 7;

- control: on-off, $\pm 0.5^{\circ} \mathrm{C}$;

- temperature of the adjacent rooms: the same of Room 1;

- internal gains: according to Table 8;

- infiltration and ventilation: $0.3 \mathrm{~h}^{-1}$ with external air temperature.

Table 7: Schedule of the thermostat during intermittent operation.

\begin{tabular}{|c|c|c|}
\hline \multirow{2}{*}{ Time } & \multicolumn{2}{|c|}{ Air temperature set-point $\left[{ }^{\circ} \mathbf{C}\right]$} \\
\cline { 2 - 3 } & Room $\mathbf{~}$ & Room $\mathbf{~}$ \\
\hline $6 \mathrm{am}-9 \mathrm{am}$ & 20 & 24 \\
\hline $9 \mathrm{am}-4 \mathrm{pm}$ & 16 & 20 \\
\hline $4 \mathrm{pm}-10 \mathrm{pm}$ & 20 & 24 \\
\hline $10 \mathrm{pm}-6 \mathrm{am}$ & 18 & 22 \\
\hline
\end{tabular}

Table 8: Schedule of internal gains.

\begin{tabular}{|c|c|c|}
\hline \multirow{2}{*}{ Time } & \multicolumn{2}{|c|}{ Internal gains [W] } \\
\cline { 2 - 3 } & Room 1 & Room 2 \\
\hline $7 \mathrm{am}-10 \mathrm{pm}$ & 10 & 10 \\
\hline $10 \mathrm{pm}-7 \mathrm{am}$ & 70 & 10 \\
\hline
\end{tabular}

The design value of the mean fluid temperature was $31.7^{\circ} \mathrm{C}$ for System 1 and $30.4^{\circ} \mathrm{C}$ for System 2 . Choosing a temperature difference between supply and return in design conditions equal to $3^{\circ} \mathrm{C}$, the supply temperature is $33.2^{\circ} \mathrm{C}$ for System 1 and $31.9^{\circ} \mathrm{C}$ for System 2 . Considering the useful heat flux towards the heated rooms and the losses on the opposite side, a mass flow rate of $90 \mathrm{~kg} / \mathrm{h}$ and $103 \mathrm{~kg} / \mathrm{h}$ was calculated for Room 1 and Room 2 respectively.

Two kinds of simulations were performed, one with no limits on the power available from the water side and one with a limit of $5 \mathrm{~K}$ in the temperature difference between supply and return, i.e. $525 \mathrm{~W}$ and $600 \mathrm{~W}$ for Room 1 and Room 2 respectively. The second case is representative of a radiant system directly connected to a heat pump, while the first one is more representative of a heating system with a storage tank.

The results of the simulations of the first 2 days of December of Room 2 are shown in Figure 7: the air temperature, the surface temperature of the floor, the supply water temperature, the temperature difference between supply and return and the thermal power exchanged by the fluid flowing in the pipes are plotted. As it can be seen, the thin-screed radiant system (System 2) turns on more frequently than the traditional one (System 1), because of its lower thermal inertia, which makes the floor surface to warm up faster, but also to cool down faster after the set-point is reached. During intermittent operation of System 1, the set-point of the time slot from 6:00 to 9:00 is reached only at 9:00, even if the radiant system has already turned on at 3:00 and even if the set-back is only $2^{\circ} \mathrm{C}$ lower. System 2 is faster, but it needs to be turned on earlier in order to reach the set-point.

When the water temperature difference which can be supplied by the production system is limited (simulations with limited power) and the radiant system turns on, the supply fluid temperature does not reach the set value because the temperature level of the fluid inside the pipes has decreased during the time period in which the radiant system was off and time is needed to heat up the structures. Gradually the screed warms up and the set value of the supply fluid temperature is reached; then the heat exchange between the screed and the fluid flowing in the pipes decreases (i.e. the fluid temperature difference decreases). As it can be seen, the supply fluid takes also more than 3 hours (for System 1 in intermittent operation) to reach the set value.

When the production system has no limit (simulations with unlimited power) and the radiant system turns on, the supply fluid temperature is immediately the set value and the fluid temperature difference can reach up to $7^{\circ} \mathrm{C}$ and $11^{\circ} \mathrm{C}$ for continuous and intermittent operation respectively. As the screed warms up the difference decreases. In this second case the radiant system is obviously faster and the number of on-off is higher.

The thermal energy need calculated from the results of the simulations is shown in Table 9. As it can be seen, no significant difference was found between the two kinds of radiant floor systems and between continuous and intermittent operation. It is useful to remember that in the case of intermittent operation the supply fluid temperature was the same which was set in the case of continuous operation and that the thermostat set-point was hardly reached. 
Table 9: Specific thermal energy need during continuous and intermittent operation with limited $(L)$ and unlimited (U) thermal power.

\begin{tabular}{|c|c|c|c|c|c|}
\hline \multirow{2}{*}{ System } & \multirow{2}{*}{$\begin{array}{c}\text { Operation } \\
\text { modality }\end{array}$} & \multicolumn{3}{|c|}{ Thermal energy need $\left[\mathrm{kWh} / \mathrm{m}^{2}\right]$} \\
\cline { 3 - 6 } & & \multicolumn{2}{|c|}{ December } & \multicolumn{2}{|c|}{ March } \\
\cline { 3 - 6 } & $\mathrm{L}$ & $\mathrm{U}$ & $\mathrm{L}$ & $\mathrm{U}$ \\
\hline 1 & continuous & 14.4 & 14.5 & 11.2 & 11.4 \\
\hline 1 & intermittent & 14.3 & 14.7 & 11.5 & 11.8 \\
\hline 2 & continuous & 14.4 & 14.4 & 11.2 & 11.3 \\
\hline 2 & intermittent & 13.8 & 14.4 & 11.2 & 11.5 \\
\hline
\end{tabular}

\section{Conclusions}

In the present work the performance of a floor radiant system with a reduced thickness of the screed was studied in comparison to a traditional floor radiant system. The investigation was both by means of field measurements in two flats of a new building, and theoretical, by means of dynamic simulations of the two systems under the same boundary conditions. The measurements of the air temperature, surface temperature of the floor and fluid temperature taken during 6 days of continuous operation and 6 days of intermittent operation of the heating systems were used to validate a numerical model which takes into account the dynamic behaviour of building structures as well as the transient operation of fluid in the embedded pipes.

Simulations under the same boundary conditions were then performed for the two kinds of floor radiant heating systems and no significant difference was found in the thermal energy need. The thin-screed system presents a lower response time, but intermittent operation does not lead to a lower energy consumption. Moreover, if the supply fluid temperature is the same used during continuous operation, the set-point is hardly reached during short time-slots. To ensure comparable indoor conditions in the occupied time periods, the radiant system should be turned on earlier or the supply fluid temperature should be increased, with resulting higher energy consumption.

From the analysis of the temperature inside the rooms, a negligible difference was found between air and operative temperature for both the radiant systems.

The coupling of the emission system with the production system is an interesting issue to be further investigated, since the fluid temperature difference available from the production system significantly affects the transient operation of the radiant system and the time needed to reach the indoor set-point.

\section{Aknowledgments}

The authors would like to thank Gruppo Furlan Srl and Opice Srl for allowing and managing the measurements in the building and ARPAV for supplying the weather data of Padova.

\section{References}

ARPAV, Agency for Environmental Prevention and Protection of Veneto Region. 2018. http://www.arpa.veneto.it
Athienitis, A.K., Chen, Y. (2000). The effect of solar radiation on dynamic thermal performance of floor heating systems. Solar Energy 69, 229-237.

Berglund, L.G., Gagge, A.P. (2012). Human response to thermal conditions maintained in an office by radiant ceiling, baseboard, forced air and floor heating systems. ASHRAE Transactions 91, 488-502.

Blomberg, T. (1999). HEAT2 - A PC-Program for Heat Transfer in Two Dimensions. Manual with Brief Theory and Examples. Lund Group for Computational Building Physics. Lund (SE).

De Carli, M., Tomasi, R. (2009). A critical review on heat exchange coefficients between heated and cooled horizontal surfaces and room. Proceedings of the 11th Roomvent 2009 Conference. Busan (KR), 24-27 May 2009.

De Carli, M., Tonon, M. (2011). Effect of modelling solar radiation on the cooling performance of radiant floors. Solar Energy 85, 689-712.

De Carli, M., Scarpa, M., Tomasi, R., Zarrella, A. (2012). DIGITHON: A numerical model for the thermal balance of rooms equipped with radiant systems. Building and Environment 57 , 126-144.

Fisher, D.R., Pedersen, C.O. (1997). Convective heat transfer in building energy and load calculation. ASHRAE Transactions 103, 137-148.

International Organisation for Standardisation (2015). Building environment design. Design, dimensioning, installation and control of embedded radiant heating and cooling systems (ISO 11855).

Klein, S.A. (2011). TRNSYS 17. Volume 3. Standard component library overview, 67-69. Solar Energy Laboratory, University of Wisconsis, Madison (USA).

Külpmann, R.W. (1993). Thermal comfort and air quality in rooms with cooled ceilings - Results of scientific investigations. ASHRAE Transactions 99, 488-502.

Kusuda, T. (1969). Thermal response factors for multilayer structures of various heat conduction systems. Ashrae Journal 11, 64.

Olesen, B.W. (1997). Possibilities and Limitations of Radiant Floor cooling. ASHRAE Transactions 103(1), 42-48.

Shoemaker, R. W. (1954). Le chauffage par rayonnement. Editions Eyrolles. Paris (FR).

Stephenson, D.G., Mitalas, G.P. (1967). Cooling load calculation by thermal response factor method. ASHRAE Transactions 73, 1-7.

Weber, T., Jóhannesson, G., Koschenz, M., Lehmann, B., Baumgartner, T. (2005). Validation of a FEMprogram (frequency-domain) and a simplified RCmodel (time-domain) for thermally activated building component systems (TABS) using measurement data. Energy and Buildings, 37(7), 707-724. 


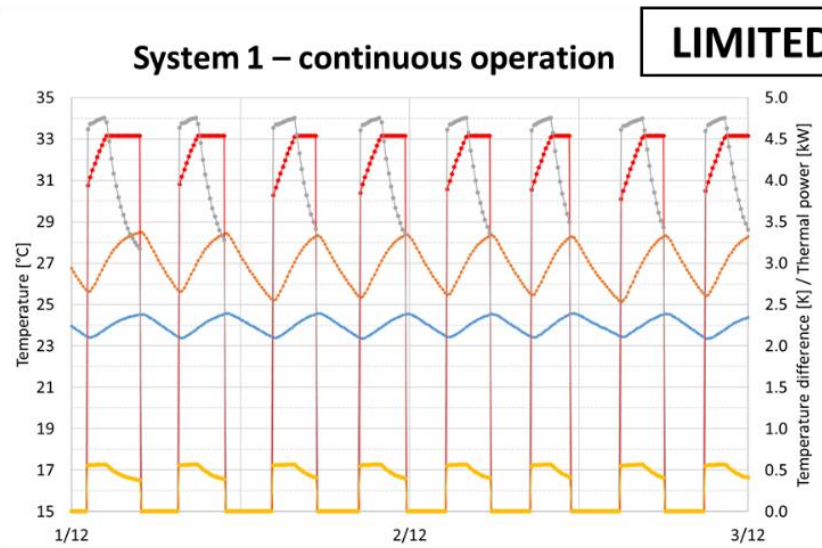

\section{POWER}

System 1 - intermittent operation
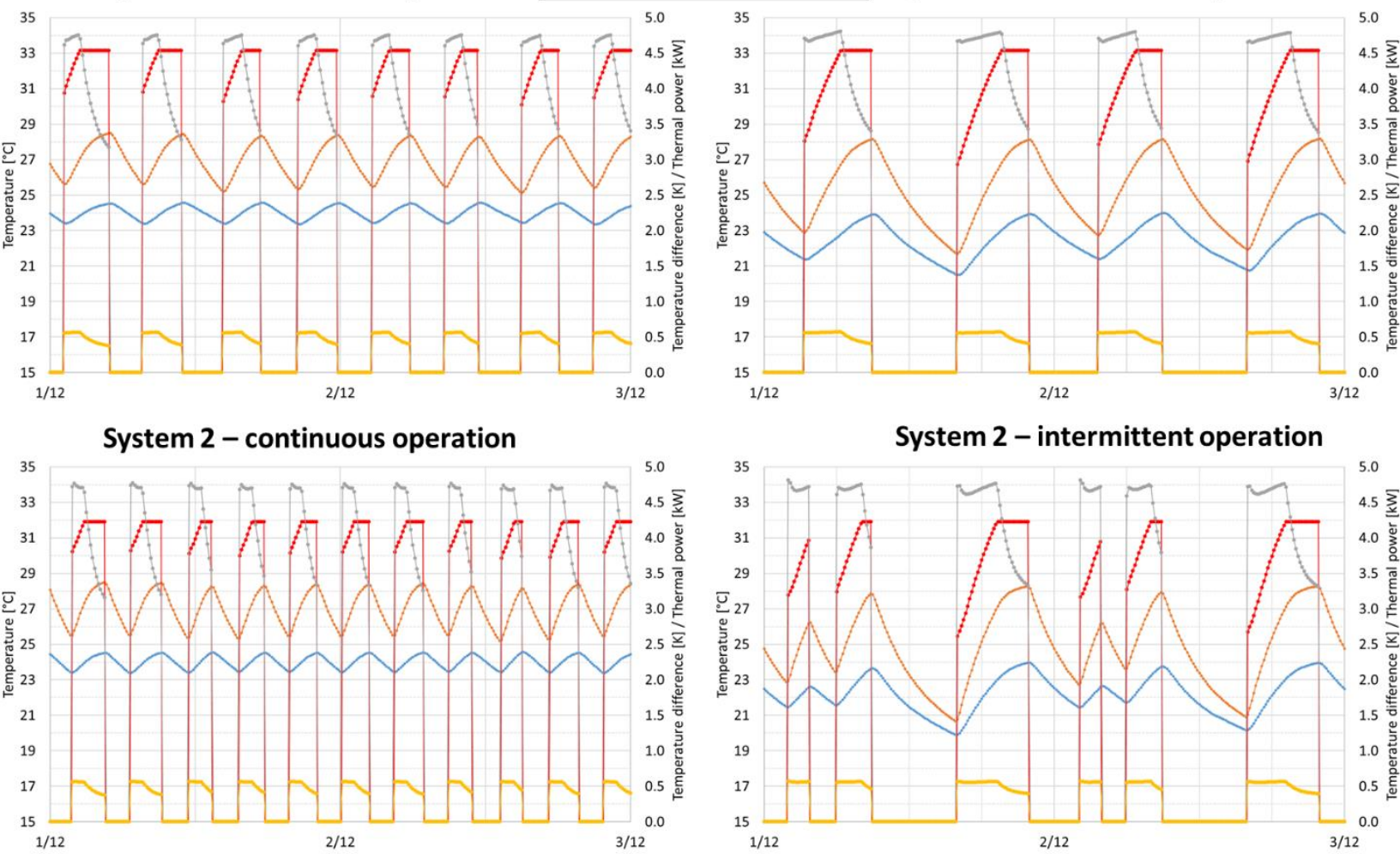

System 2 - intermittent operation
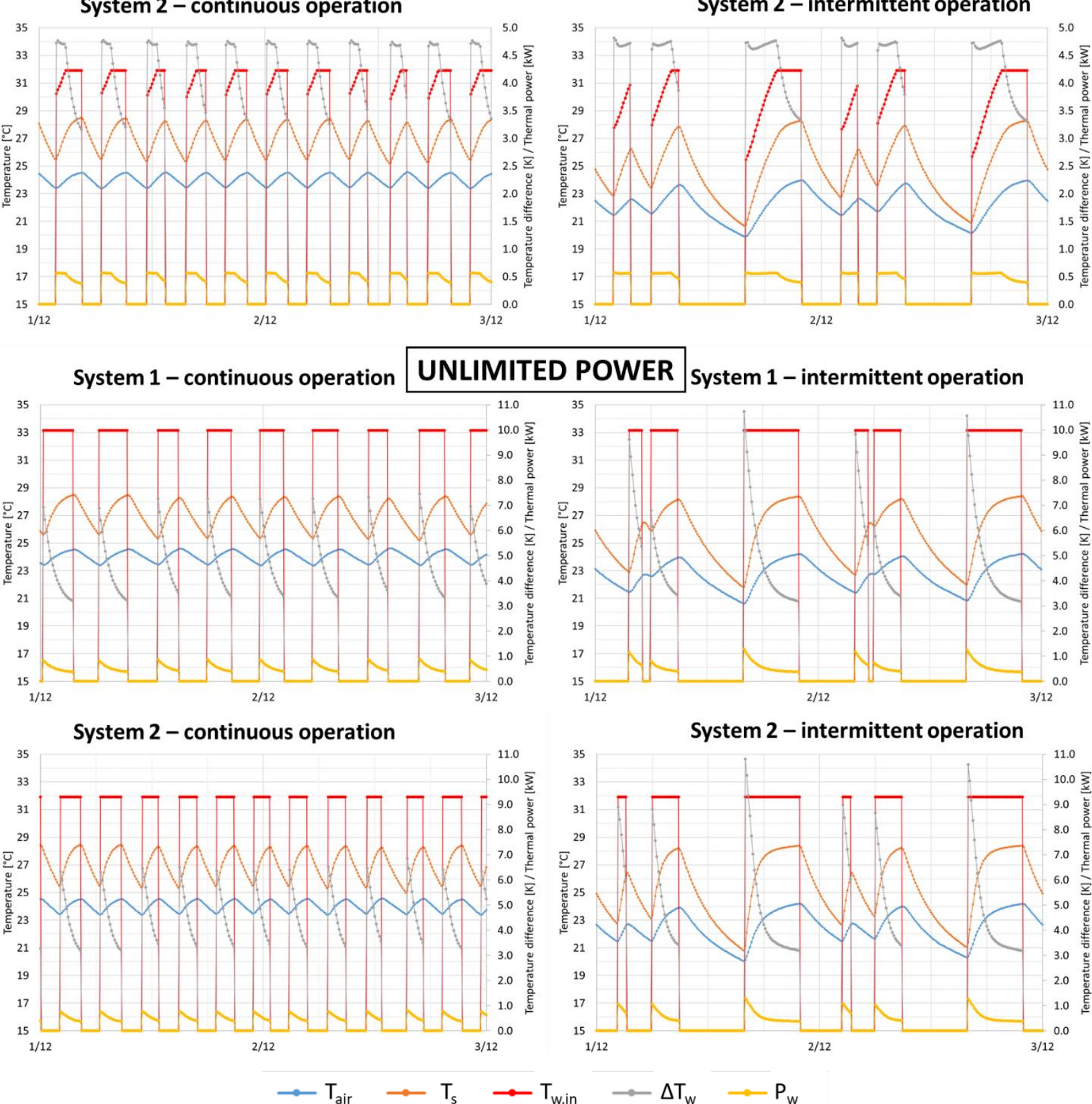

Figure 7: Results of the simulations of December for Room 2 with System 1 and System 2. 